\title{
The Chemical Society of Geneva, a Vital Link Between the Academy and the City
}

\author{
Jean-Pierre Barras ${ }^{\star a}$ and Hans Hagemann ${ }^{b}$
}

\begin{abstract}
The historical background and the current activities of the Chemical Society of Geneva are described. Founded 88 years ago from the merger of three student associations, the Society today connects some 190 chemists and biochemists from all professional horizons. The Society's main goal is to promote molecular sciences studies and applications in Geneva. In addition to regularly organizing scientific lectures and visits, it sponsors major scientific seminars and grants annual awards to secondary school pupils and bachelor students.
\end{abstract}

Keywords: Chemical Society of Geneva

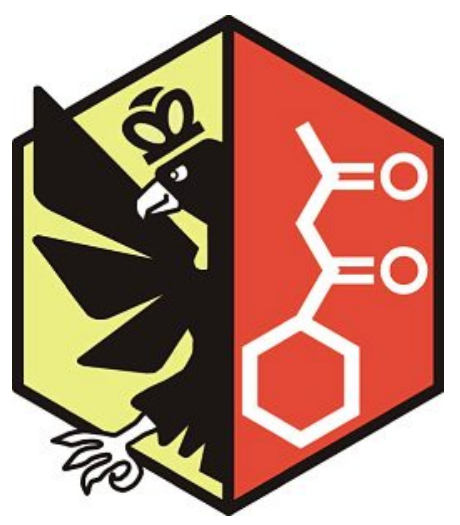

The 450th anniversary of the simultaneous foundation, at the instigation of Jean Calvin, of Geneva's first state organized private and public schools (schola privata and schola publica or collège and académie) also happens to coincide with a jubilee year in the far shorter history of the Chemical Society of Geneva. The latter indeed celebrates this year the 75th anniversary of its metamorphosis from a student association into the scientific society dedicated to the advancement of molecular sciences it has remained up to this day.

${ }^{\star}$ Correspondence: Dr. J.-P. Barras ${ }^{a}$

President of the Chemical Society of Geneva

Tel.: + 41227809948

Fax: + 41227809040

E-mail: j-pierre.barras@givaudan.com

aGivaudan Suisse SA

Développement des procédés

Chemin de la Parfumerie 5

$\mathrm{CH}-1214$ Vernier

bUniversité de Genève

Département de Chimie Physique

Sciences II

Quai Ernest-Ansermet 30

$\mathrm{CH}-1211$ Genève 4
The historical roots of the Chemical Society of Geneva can be traced back to the foundation, in 1905, of the first of the three associations which eventually became part of it, the '(Professor Duparc's) Analytical Chemistry Laboratory's Former Students' Association'. The founder members' chief motivation was to keep in touch with each other after the end of their studies and to lend themselves mutual support either in case of personal difficulties or in the advancement of their scientific careers. A few years later, spurred by their colleagues' move, the teachers, students and graduates of the School of Chemistry's two other departments, namely the 'Theoretical and Technical Chemistry Laboratory' and the 'Organic and Inorganic Chemistry Laboratory', also separately set up their own professional associations.

The obvious next step, the merger of those three separate organizations into a single entity, was taken on July 6th 1921 during the course of a purposely convened common general assembly (Fig. 1). The new society took the rather tongue twisting name of 'Geneva's School of Chemistry's Students' and former Students' Association' (or AECG for short, an acronym derived from its French title ...) and Professor Emile Briner (Fig. 2) was elected as its first President. At over 180, the association's initial membership was already almost on par with its current strength of some 190 individual members.

Although the AECG had already been in existence for 13 years, the present day Chemical Society of Geneva can fairly be said to be born in 1934 rather than in 1921 . It was indeed on February 14th 1934, during their annual general assembly, that the AECG's members passed the statutes, which, with minor modifications, continue to govern the Society's activities nowadays. The main far-sighted steps taken during this memorable meeting were: a) To open up membership to any person implied or interested in the advancement of chemical sciences in Geneva, in addition to the School of Chemistry's teachers, graduates and undergraduates;

b) To commit the association to the promotion and furthering of theoretical and applied chemical sciences in Geneva by all the means it could dispose of.

The association's new ambitions and statutory goals called for a new name and, in the course of this same general assembly, the former AECG became the 'Chemists' Association of Geneva'. This title was slightly altered to the current one in 1960 , at the same time as provision for collective membership (open to other associations or (bio)chemical companies) was incorporated into the statutes.

Because of the lack of public assistance schemes for the unemployed people hit by the economic depression of the early 1930s, one of the AECG's initial roles was to collect information about vacant positions in the area and to give jobless chemists advice and support. While manifesting themselves nowadays in different ways, solidarity and mutual support among members have remained the Society's raison d'être ever since. Scientific and social events regularly provide members from all professional horizons opportunities to meet and exchange information and ideas. These discussions mostly take place after the scientific lectures, during the traditional informal receptions, and during the annual excursions and banquets. In accordance with the Society's cross specialisations and cross generations federating willingness, the members of the Board are always chosen in roughly equal parts from the academic sphere and from the public or private sector. It is also part of the Board's policy to propose can- 


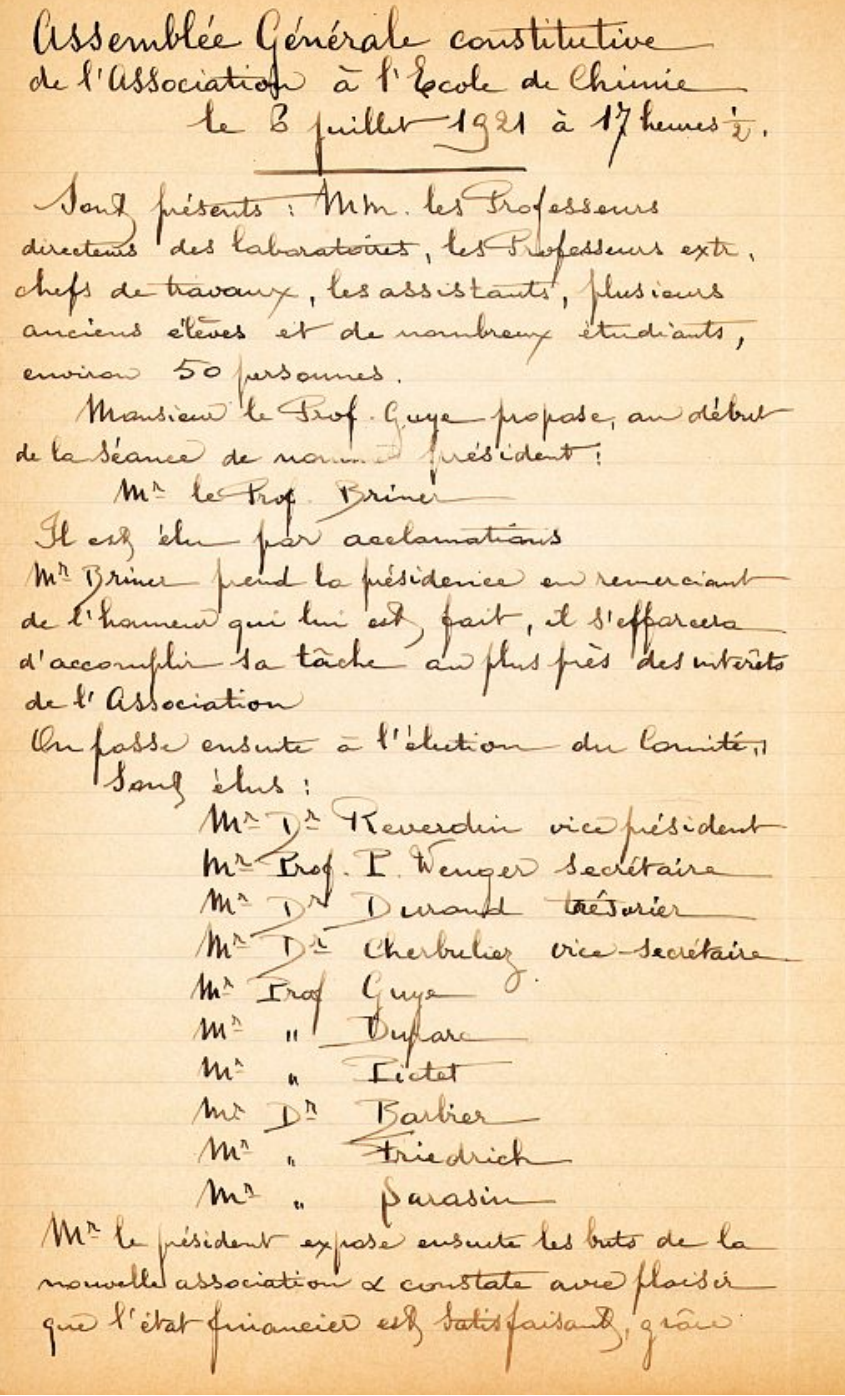

Fig. 1. Front page of the minutes of the AECG's constitutive assembly (July 6th, 1921) with the composition of the first Board.

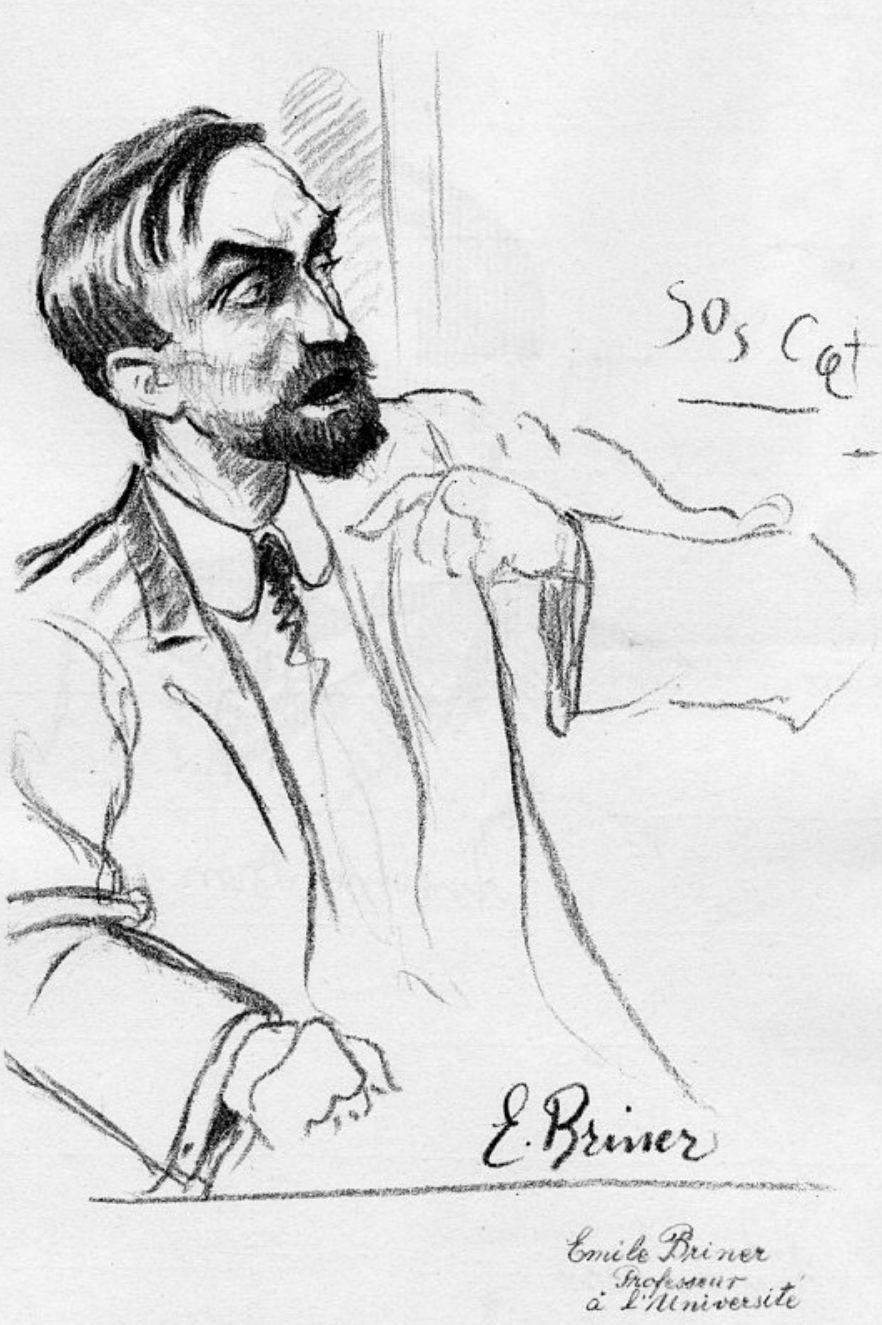

Fig. 2. Professor Emile Briner (1879-1965), president of the Chemical Society from 1921 to 1924 and from 1941 to 1944; drawing by Oscar Lazar, 1922 (BGE, Centre d'iconographie genevoise). didates alternatively from the academic sector and industry to the general assembly every time a new President has to be elected.

Over the years the Chemical Society of Geneva's dedication to the advancement of molecular sciences has taken several different forms. These activities can be broadly classified into three different categories: a) Scientific lectures;

b) Subsidies for equipment and financial contribution to professional specialised molecular sciences seminars organized in Geneva as well as general public scientific events;

c) Annual awards for secondary school pupils (for the best dissertation in the field of molecular sciences) and for undergraduate chemistry and biochemistry students (bachelors).

From the very beginning, organizing scientific lectures has been one of the Board's main activities and many distinguished speakers have been invited to de- liver talks (see the Table for some examples). Some of the lectures, in addition to the annual awards ceremonies for bachelor students (Fig. 3), are organised in common with the University of Geneva's Chemistry Department. Other events are staged in partnership with fellow local scientific societies. Open to the general public, the Society's lectures constitute a privileged way of spreading new scientific knowledge among the members and within the local community. They also offer the invited lecturers an opportunity to introduce and discuss their research, and potential applications, to a broader and more diversified audience than is feasible in specialised seminars. While most of these lectures have either chemistry or biochemistry as their main themes, other topics such as medicine, biology, physics, gastronomy, fragrances, energy supplies, industrial safety and sciences' history, for example, also regularly feature in the programme. In addition to these regular lectures, the
Society has also offered for a while, during the 1960s, refresher and further education courses to its members from the local chemical industry.

As stated previously, helping Geneva to maintain its position as centre of excellence for research in molecular sciences and the communication of scientific results is one of the Society's key commitments. In the past, the Chemical Society has occasionally helped the School of Chemistry to acquire the books or the equipment it needed by means of subsidies. In more recent times, the Society's financial support has only been asked for, and granted to, the organizing committees of the major specialised conferences and seminars which regularly take place in Geneva. Intended to encourage graduate studies in Geneva, the recently instituted annual awards for the best chemistry and biochemistry bachelor students are also part of this promotion effort.

One of the most challenging problems facing the Chemical Society of Geneva is 
Table. Selection of conferences by prominent scientists organized by the society

\begin{tabular}{|c|c|c|}
\hline Date & Speaker & Title \\
\hline 6.2 .1928 & Victor Grignard & Hydrogénation catalytique sous pression réduite \\
\hline 14.10.1937 & Sir Venkata Raman & Diffusion of light by colloids \\
\hline 18.3.1938 & Paul Karrer & $\begin{array}{l}\text { Bedeutung der Carotinoide und Flavine im } \\
\text { biologischen Geschehen }\end{array}$ \\
\hline 8.3 .1940 & Leopold Ruzicka & $\begin{array}{l}\text { Von den insektentötenden Stoffen zu den } \\
\text { Sexualhormonen }\end{array}$ \\
\hline 10.3.1961 & Jean Monod & $\begin{array}{l}\text { Données nouvelles sur le mécanisme de } \\
\text { l'adaptation enzymatique }\end{array}$ \\
\hline 20.11.1970 & Jean-Marie Lehn & $\begin{array}{l}\text { Les cryptates, une classe nouvelle de complexes } \\
\text { cationiques organiques }\end{array}$ \\
\hline 14.5.1971 & $\begin{array}{l}\text { Paul von Rague } \\
\text { Schleyer }\end{array}$ & $\begin{array}{l}\text { Insights on Carbonium ions provided by M.O. } \\
\text { calculations }\end{array}$ \\
\hline 16.11.1971 & Lord George Porter & Chemistry in Microtime \\
\hline 1.6.1978 & Carl Djerassi & Futures Prospects in Insect Control \\
\hline 16.6.1993 & Edmond Fischer & Tyrosine phosphatase et la transformation cellulaire \\
\hline 24.2.1998 & Denis Duboule & Avons-nous besoin du génie génétique? \\
\hline 8.2.1999 & Olivier Kahn & Hystérésis et effet mémoire en chimie moléculaire \\
\hline
\end{tabular}

how it can help to promote chemistry, and to better explain the fundamental role of molecular sciences, to the younger generations and to the general public at large. This is not an easy task because of the comparatively low priority given to scientific matters in current educational schemes and

of the frequently biased treatment chemistry receives from the general press and TV channels. The problem has nevertheless to be tackled if the molecular sciences want to recruit the talented young people they need. In the future, sustaining a seemingly endlessly expanding human population on

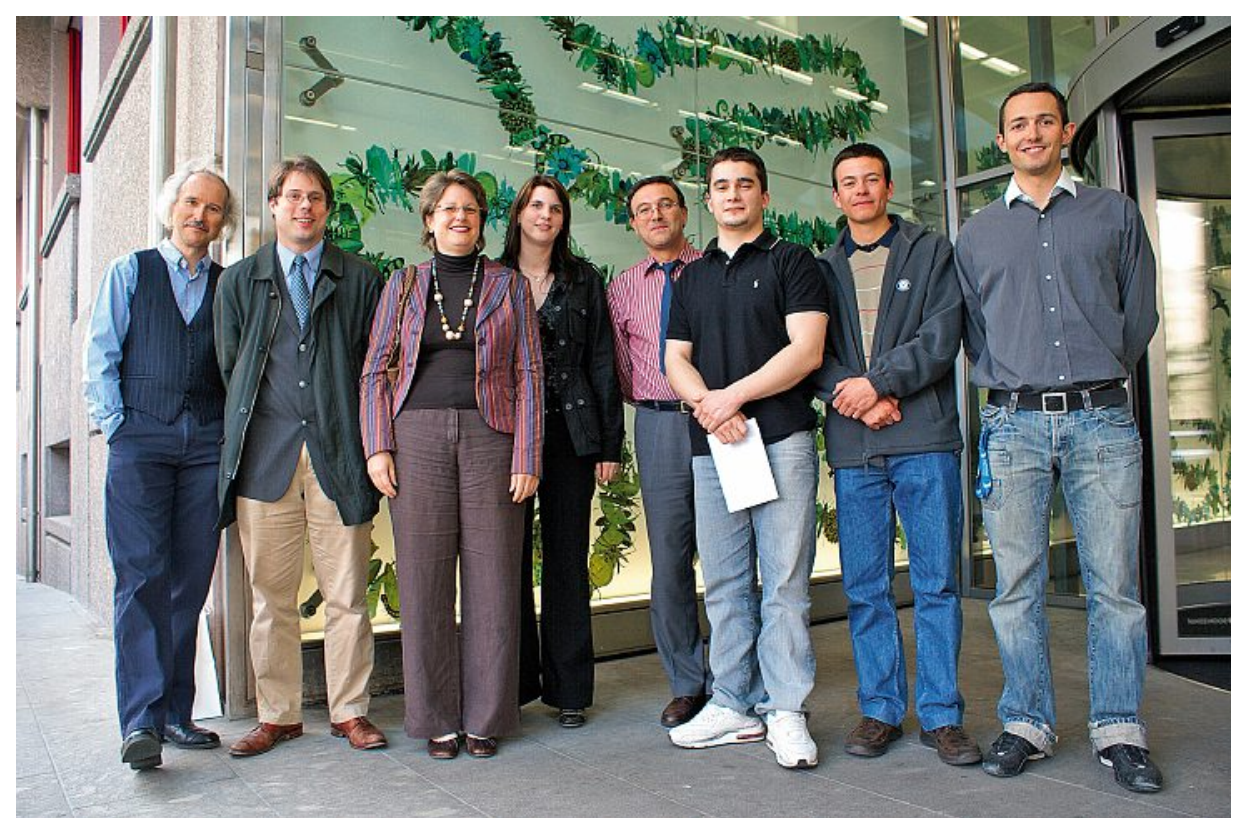

Fig. 3. Laureates for the best bachelor and master theses in chemistry and biochemistry at the University of Geneva in 2009. From left to right : Prof. Andreas Hauser, president of the Section de chimie et biochimie; Dr Olivier Haefliger, Firmenich S.A.; Ms Elisabeth Vock, Syngenta Crop Protection S.A.; Ms Muriel Vocat, Syngenta award for the best MSc in biochemistry; Dr JeanPierre Barras, president of the Chemical Society of Geneva; M. Fedor Romanov-Michaëlides, Chemical Society of Geneva award for the best BSc in biochemistry; M. Pierre Charbonnaz, Chemical Society of Geneva award for the best BSc in chemistry; M. Ludovic Gremaud, Ciba award for the best MSc student in chemistry. limited resources in an environmentally acceptable way definitely will not call for less chemistry, as some political factions claim. On the contrary, a more intimate understanding of the properties and transformation of molecular systems by the best available scientists will be necessary. In this context, the Society's annual awards for scientifically minded secondary school's pupils constitute a first step to establish a tighter relationship with the younger generations. Other schemes yet to be devised will however undoubtedly have to be implemented in the future for this goal to be achieved.

Making chemistry responsible for the worst environmental side effects of the mercantile society in which we live, and of the consumer behaviour which we all (to some extent) practise, is akin to throwing the baby away with bath water. It is a hypocritical way of blaming a fundamental science for the sometimes careless, or even, at times, deliberately criminal way its discoveries have been used. Although the risk of abusive application will always exist, fundamental research remains today as necessary as ever, if not more so. When it comes to meet mankind's needs in a more sustainable way, to correct the errors of the past and to avoid the making of new ones, thoughtful application of scientifically established knowledge is infinitely superior to precipitated moves inspired by irrational beliefs or desires for political visibility. This is the conviction and the fundamental message which the Chemical Society of Geneva will continue to promote and to dispense in the future.

The authors thank Dr Didier Perret for his help with the illustrations, and the BGE, Centre d'iconographie genevoise, for allowing the publication of the portrait of E. Briner.

Received: September 23, 2009 